Chirurgia (2017) 112: 509-511

No. 5, September - October

Copyright@ Celsius

http://dx.doi.org/10.21614/chirurgia.112.5.509

\title{
Laparoscopy in Abdominal Emergencies - Past and Future
}

\author{
Selman Uranues \\ Section for Surgical Research, Department of Surgery, Graz, Austria
}

Corresponding author:

Selman Uranues, MD,Dr. h.c.,FACS,

FEBS (Emerg.Surg.)

Professor and Head

Section for Surgical Research

Department of Surgery

Medical University of Graz

Auenbruggerplatz 29

8036 Graz, Austria

E-mail: selman.uranues@medunigraz.at
Received: 05.092017

Accepted: 10.09 .2017
In 1985, the laparoscopic removal of a gallbladder ushered in a new era in abdominal surgery. Laparoscopy thereafter was more quickly and widely accepted than had ever been the case with a new technique; it is now used routinely in surgery on every abdominal organ and in every possible indication.

From very early times, physicians have wanted to look into the human body and view hollow organs through the body's natural openings. Early on, a spoon-like speculum was used to look into the pharynx, anus or vagina, with mirrors reflecting candlelight or sunlight into the opening. In 1806, Bozzini's endoscope introduced modern endoscopy, though the real breakthrough came about later in that century and was based on the catheter, one of the oldest medical instruments that had been used for more than 3000 years to allow drainage of the bladder. It was almost a century until Maximilian Nitze collaborated with Josef Leiter, an innovative Viennese instrument maker, to create an endoscope for practical use. Although Kelling performed the first esophago-gastroscopy in 1898, Schindler, using a semiflexible gastroscope designed by Wolf, came to be recognized as the father of gastroscopy.

The German surgeon Kelling performed the first laparoscopy in 1905 , just after the turn of the $20^{\text {th }}$ century, though he called it a "coelioscopy." Based on his experiments with pneumoperitoneum in animals, he intended to compress the stomach and duodenum to stop upper gastrointestinal bleeding. Important publications on early experience with laparoscopy included those by the Swedish internist Jacobeus (1910), Ruddock, an American (1937), and Kalk, a German (1951). The spring-loaded needle introduced by Veress in 1938 is still used today in 
slightly modified form to create a pneumoperitoneum.

Well before laparoscopy made inroads into abdominal surgery, gynecologists were using it for diagnostic procedures and sometimes treatment as well. Semm, a German gynecologist, performed the first laparoscopic appendectomy and went on to do many more.

With these preliminary developments, the stage was set for a new era in surgery. Mühe's report of a first laparoscopic cholecystectomy at the German Surgical Congress in 1985 in Munich was published in Langenbecks Archiv für Chirurgie but remained unnoticed until Mouret's publication in 1987, when the laparoscopy boom began.

Considering the fact that each year about 450 women and 180 men per 100,000 population are hospitalized for acute abdominal pain, most commonly for non-specific abdominal pain (15.9-28.1\%), acute biliary disease (2.9-9.7\%), and bowel obstruction or diverticulitis (9), it is unsurprising that laparoscopic emergency abdominal surgery has seen a continuous upward trend since its introduction more than 30 years ago.

In most industrialized countries, trauma is the most common cause of death in the younger population under age 50. About one-half of the deaths take place within minutes at the site of the accident; these are usually severe head and cardiovascular injuries. Thirty percent of the deaths occur within a few hours after the injury and conservative estimates indicate that approximately $20-30 \%$ of these accident victims could be saved with timely diagnosis and proper treatment. Laparoscopy has come to play an increasing role in this setting. It is primarily a diagnostic measure, but can also be applied therapeutically.

Future laparoscopic instruments will be thinner, more precise, and multifunctional so that they will not have to be drawn out and exchanged so frequently during surgery. With more assisting devices available to the surgeon, the operating room will become a lonely place, and the one-person team is no longer unusual in laparoscopic surgery. Surgical robots will play an important part in these developments and remote surgery will become routine. For especially demanding laparoscopic procedures that require a highly experienced specialist, patients will not be brought to the specialist but will undergo surgery in their own hospitals with the specialist operating telemetrically, using video assistance via smart glasses, smartphone or mobile device from a distant operating room (http://www.evocall.evolaris.net/).

Miniaturized instruments, mini-robots and other devices to perform specific tasks will be inserted into the body and, depending on how they are programmed, will perform tasks automatically and independently. These intelligent devices could also be inserted through natural orifices and controlled remotely by a surgeon. These possibilities open up a new dimension of technical knowledge and ability that the surgeon will have to master. Today, it is absolutely essential that the surgeon be thoroughly familiar with the technical details of equipment and instruments, not only for laparoscopic surgery.

A lay person would probably take it for granted that in emergencies, surgeons have a highly developed rationale for choosing a laparoscopic approach. Most of the relevant literature, however, comprises case reports, uncontrolled case series, or comparison studies, often with selection flaws and capable only of suggesting feasibility, whereby feasibility does not necessarily imply a recommendation. It is the individual surgeon's utmost responsibility to choose the best surgical approach depending on a number of factors, including the surgeon's own expertise and competence, the infrastructure available, and the experience of the entire surgical team.

\section{References}

1. Bozzini P. Lichtleiter, eine Erfindung zur Anschauung innerer Teile und Krankheiten, nebst der Abbildung". Light conductor, an invention for viewing internal parts and diseases, together with illustrations. Journal der practischen Arzneykunde und Wundarzneykunst (Journal of Practical Medicine and Surgery). 1806;24:107-24.

2. Nitze M. Lehrbuch der Kystoskopie. J.F. Bergmann, Wiesbaden, eds. 1889.

3. Kelling. Arch.f.Verdauungskrankh. 1905;11:550

4. Schindler R. Gastroscopic observation concerned with the gross anatomy oft he stomach: the musculus sphincter antri, observation 
of the position of the stomach, the mucosal folds. Amer J Dig Dis 1936;3:149-53.

5. Jacobaeus HC. Kurze Übersicht über meine Erfahrungen mit der Laparothorakoskopie. Münch Med Wochenschr. 1911; 58:2017.

6. Kalk H. Erfahrungen mit der Laparoskopie (Zugleich mit Beschreibung eines neuen Instrumentes). Z. Klin. Med. 1929; 111:303

7. Mühe E. Die erste Cholezystektomie durch das Laparoskop.
Langenbecks Archiv. 1986;369:804.

8. Reynolds W Jr. The first laparoscopic cholecystectomy. JSLS. 2001;5(1):89-94.

9. Grundmann RT, Petersen M, Lippert H, Meyer F. The acute (surgical) abdomen - epidemiology, diagnosis and general principles of management. Z Gastroenterol. 2010;48(6):696-706. doi: 10.1055/ s-0029-1245303. Epub 2010 Jun 1. German 